\title{
Science education reform in confucian learning cultures: policymakers' perspectives on policy and practice in Taiwan
}

Ying-Syuan Huang ${ }^{*}$ (D) and Anila Asghar

* Correspondence: ying.huang6@mail.mcgill.ca Department of Integrated Studies in Education, Faculty of Education, McGill University, 3700 McTavish Street, Montreal, QC, Canada

\begin{abstract}
This qualitative inquiry project investigates the political and policy discourses related to education reform in Taiwan. Specifically, it examines the science education reform policies and policy leaders' vision for the reform. This work also reveals the unique challenges involved in implementing contemporary science education approaches in a Confucian learning culture. Data sources included reform policy documents and interviews with policymakers. Thematic and constant comparative methods were used to analyze these data. The Foucauldian framework on governmentality served as a lens to examine the historical and political conditions which shaped policy leaders' rationale for educational change and the strategies that they used to implement the reform policies in local educational institutions. Policymakers identified a number of critical challenges related to the reform initiative, emphasizing that social and cultural traditions in Confucian learning cultures presented significant obstacles to the implementation of inquiry-based and learner-centered approaches in Taiwanese schools. These findings have important implications for future policy and curriculum initiatives in East Asian cultures.
\end{abstract}

\section{Introduction}

Over the past two decades, the Taiwanese government has been making earnest efforts to transform the national science education curriculum for elementary and secondary levels (Ministry of Education, Taiwan 2003a). Aligned with global trends in science education, the key objectives of these reforms are to cultivate students' conceptions of "democracy" and their "ability to think, judge and create" (Ministry of Education, Taiwan 2003a), p 8). Through a constructivist approach, the new curriculum aims to develop a set of competencies related to scientific literacy, such as "independent thinking" and "potential for active learning" (Ministry of Education, Taiwan 2003a), p. 14) among learners in Taiwan.

However, a large number of Taiwanese teachers and parents continue to express their opposition to the new science standards and curriculum even after a decade of implementation. Tobin and McRobbie (1996) argued that most students and parents in Taiwan seem to be convinced of the effectiveness of the traditional teacher-centered pedagogy. Similarly, other scholars have suggested that Taiwanese teachers often feel

(c) 2016 The Author(s). Open Access This article is distributed under the terms of the Creative Commons Attribution 4.0 International License (http://creativecommons.org/licenses/by/4.0/), which permits unrestricted use, distribution, and reproduction in any medium, provided you give appropriate credit to the original author(s) and the source, provide a link to the Creative Commons license, and indicate if changes were made. 
responsible to prepare students to pass annual national entrance examinations, such as the Joint Entrance Examination of Universities and Colleges (Berry 2011; Yang et al. 2008). Constructivist teaching and learning strategies are perceived to be ineffective for preparing students for the traditional competitive examinations (Kyriacou and Chien 2004; Lu et al. 2010; Tsai and Kuo 2008).

This article is part of a larger research project in which policymakers' and science teachers' perspectives on Taiwan's reform were explored (Huang 2014) to better understand the challenges involved in implementing the reform-based curriculum. In particular, our analysis of data obtained through interviews with science teachers revealed that most teachers felt unprepared to adapt and employ reform-based pedagogies in their teaching (Huang 2014; Huang and Asghar, in press). Many teachers asserted that the examination system in Taiwan focuses primarily on knowledge recall. Some teachers also believed that the new science curriculum and pedagogy were inadequate for preparing students for the national standardized exams. Thus, the perceived disconnect and tension between the curriculum goals and the national examination system have become a potential source of resistance on the part of teachers. However, while teachers' perspectives on curriculum reform have been widely studied, there has been comparatively little focus on policymakers' views about the development of science education reform.

This article sheds light on the vision of Taiwanese education reformers and on their perspectives on the barriers to promoting learner-centered pedagogy through inquirybased science learning in Taiwanese schools. The primary goal of this article is to gain an in-depth understanding of the challenges and concerns highlighted by the policymakers regarding the implementation of the reform policies. The following research questions guide this study:

1. What is Taiwanese policymakers' vision of the science education policy?

2. What are policymakers' perspectives on the significance of education reform in Taiwan?

3. Which issues brought science education to the forefront of the reform discourse?

4. What are policymakers' views about supporting secondary science teachers in implementing the science education policy goals?

Inspired by Foucault's (1998) concept of governmentality, this work seeks to deconstruct the practices of the government by unraveling the historical conditions in which discourses about education reform took place in Taiwanese society. Similar to most Foucauldian-inspired educational policy studies (Ball 1994; Pongratz 2006; Rose and Miller 1992), this work focuses on the ways in which policymakers' values might have shaped the political discourses and the development of education policy. In the following section, we begin by explaining the concept of governmentality and how it was employed as a theoretical lens to inform this study. We then turn to the historical milieu and political discourses that shaped Taiwan's educational changes and reform movement in the 1990s.

\section{A conceptual framework of Foucault's governmentality}

Understanding the political ideologies driving the education reform policies within a complex historical milieu was central to this inquiry. Foucault (1998) argues that it is 
not possible to study the content of reform policies and the strategies used in promoting and implementing them without considering the historical context and political motivations that underpin them. Foucault (1978) developed the concept of governmentality, which has been frequently employed in policy analyses. Foucault's governmentality framework explores the connections between "forms of government and rationalities or modes of thoughts (about governing) which justify, legitimise and make the exercise of government deem rational" (Fimyar 2008, p. 4). Foucault's work on governmentality is mainly concerned with the art of government. He created this framework to explicate the wide range of techniques employed by governments to manage people's conduct through public policies. Foucault first defined government as "the conduct of conduct" (Foucault and Rabinow 1984, p. 314). The act of governing people, in his view, encompasses "a versatile equilibrium, with complementarity and conflicts between techniques" to enforce political ideologies through public policies (Foucault 1978, pp. 203-204). Olssen (1999) explained that political rationalities are created in response to pressing issues that arise in a particular historical moment.

In Foucault's (1998) view, political transitions reflect the changing rationalities of governments. Political rationality refers to the ways in which policymakers rationalize their beliefs or political actions based on certain ideas, theories, philosophies, cultural rituals, or forms of knowledge about governance (Foucault 1998; Lemke 2002). In modern liberal societies, governments rely on the exercise of power, which Foucault (1978) termed governmental technologies. Specifically, power is exercised through strategic games, such as political rule, ideological manipulation, rational argumentation, moral advice, or economic exploitation (Lemke 2002). As Fimyar (2008),

The key concepts in the analytics of government (i.e., studies into governmentality) are those of political reason and technologies of governance. While the former constitutes an ideology and discourse that was created as a response to problems of a definite historical period, the latter relates to the instrumental level and embraces the means by which particular policies are devised and implemented. (p. 4)

Governmentality plays a key role in Foucault's analysis of power (Barry 1991; Lemke 2002). It attempts to understand power "beyond a perspective" that centers on governmental domination (Lemke 2002, p. 3). In Lemke's view, "it helps to differentiate between power and domination" (p. 3). According to Foucault (1979), there is a difference between power and domination. Domination is based on unequal power relations in which one of the parties is weak and defenseless because its "margin of liberty is extremely limited" (Fendler 2010, p. 115). Power, on the other hand, enables all parties to act, respond, or react "even if the only options for action are extreme" (Fendler 2010, p. 115). While the concept of governmentality has been used in the literature to examine the discourses of power-governmental techniques in particular-in relation to economic and legal policies, relatively little research applies this conceptual tool in examining education policy reform.

Stephen Ball, a sociologist whose research focuses on the relationships between education policy and social class, often uses Foucault's concepts of governmentality and power to analyze the processes of educational policymaking. In his book Education Reform: A Critical and Post-Structural Approach, Ball (1994) examined the ways in 
which particular values of policymakers may determine the dominant discourses on education reform in the United Kingdom. In his analysis of education policy documents, Ball (1994) argued that the government officials in the Ministry of Education justified certain "authoritative allocation[s] of values" (p. 3) as "regimes of truth" (p. 22) to promote their political ideology. Drawing on Foucault's concept of power, Ball (1994) further examined how new policies have retrospectively shaped the dominant discourses on education, such that different actors might support or resist certain policies based on their institutional roles or social classes in society. In Ball's (2012) view, neoliberal education policies (e.g., performativity, nationwide standards, and accountability) have transformed the previous mode of educational discourse and emerged as a new form of power to influence local policymaking processes. Many of these authoritative allocations of values have thus been accepted and operate as the "truth" in modern society. For example, in the context of Taiwan, Chou and Ching (2012) argued that the effects of globalization on local education policies have been accepted as a regime of truth in Taiwanese society. Therefore, when studying education policy, Ball (2012) urges us to critically examine important questions, such as "whose values are validated in policy and whose are not" (Ball 2012, p. 3). Thus, a critical examination of governmentality is vital to discover the values taken for granted in the development of education policy.

In a similar vein, Trowler (2003) argued that policymakers' discourses may not represent the social reality. According to Trowler (2003), policymakers consciously or unconsciously tend to choose certain values that conceal the social reality to advance their ideologies (p. 132). For example, in his analysis, Pongratz (2006) found that the German government promoted its education reform agenda by emphasizing the importance of students' performance on international standardized assessments such as Programme for International Student Assessment (PISA). Given that the PISA exams focus on the scientific problem-solving skills that the job market requires, the German government justified the science education reform as a way to help students compete in the global economy. This governmental technology has shaped the discourse on education in Germany such that the primary goal of science learning has been framed as preparing students for the PISA test (Pongratz 2006). As an increasing number of governments around the world began to use scores on the PISA exams as a proxy for the overall quality of science education in a country, discourses about global competition and market-oriented reform in science education began to emerge as reality. As Trowler (2003) asserted, "Policy-makers, then, can and do constrain the way we think about education in general and specific education policies in particular, through the language in which they frame policies" (p. 132).

Indeed, during the interview conversations in this study, educational policy leaders discussed their visions for the science education reform in Taiwan. They believed that the reform might help to transform the philosophy and practice of education in Taiwanese and other Eastern cultures. Specifically, they believed that the impact of Confucian values on Taiwanese society might have impeded the success of inquirybased learning and learner-centered pedagogies in science classrooms (details are discussed in the Findings section). Thus, exploring the perspective of policymakers is vital for understanding shifting political ideologies and their impact on science 
education in Taiwan and other non-Western countries. In this study, the Foucauldian concept of governmentality helped in understanding the intricate dynamics of Taiwan's educational reform policies. In particular, this framework was useful in unraveling the rationalities of the government regarding education reform vis-à-vis the dominant historical and political discourses in Taiwan (Foucault 1998). As Rose (1999) argued, the significance of the concept of governmentality lies in uncovering government's practices, as well as "their presuppositions, their assumptions, their exclusion, their naiveties and their knaveries, their regimes of vision and their sports of blindness" (p. 19).

Given the importance of Taiwan's transition to democracy in shaping the education reform discourses of the 1990s, it is crucial to study the content of the policies and the strategies used to promote and implement them and to situate them in their historical and sociopolitical contexts (Foucault, 1998). In the next section, we briefly discuss the historical and political conditions that inspired the science education reform movement in Taiwan. We also illuminate the ways in which political events have shaped the discourse on Confucian values in Taiwan's educational practice. Further, we provide an overview of the curriculum changes outlined in the science education reform policy.

\section{Research context}

In 1994, Taiwan's citizens staged a mass demonstration demanding the removal of the totalitarian Kuomintang government ( $\mathrm{Tu}$ 2007). The resistance against 40 years of authoritarian rule resulted in the formation of a new democratic government in the 1990s. One of the pioneering endeavors of the newly formed government was to initiate intensive education reform. As a result, a series of reform policies were enacted to overhaul the laws pertaining to education, higher education structures, teacher preparation programs, teacher selection and placement systems, and the national curriculum for K-12 education. The goal of education reform was to decentralize Taiwan's highly regulated traditional education system to foster teacher and student autonomy (Tu 2007).

Prior to the 1994 reform, the education system in Taiwan was under the strict control of the Ministry of Education (MOE), which placed stringent restrictions on teachers' and students' freedom of expression. For example, during the authoritarian regime, they were prohibited from expressing their political opinions (Law 2004). In addition, the MOE strictly regulated teachers' didactic and pedagogical practices. For example, schools were permitted to use only the teaching materials that were prescribed by the National Institute for Compilation and Translation. Under the influence of this restrictive climate, teachers used primarily lecture-based instruction methods, and rarely or never encouraged student participation during instruction (Cai 2001).

The political movement against the government in the 1990s also challenged the traditional practices embedded in the Taiwanese education system (Law 2004). As the Minister of Education, Dr. Cheng-sheng Tu, noted in 2007, Taiwan's citizens demanded education reform in order to decentralize the education system and decision-making processes. Hailing the reform as a significant milestone in education, Tu (2007) explained the goals of the movement to reform education: 
On April 10, 1994, Taiwan's middle-class citizens organized and staged a mass demonstration demanding educational reform. The movement has become a landmark in Taiwan's history. Its main appeal was to demand the removal of all unreasonable controls and bondages imposed on education by the authoritarian government and to return to the student-centered educational liberation movement. It demanded a shift of the concepts of "de-centralization" to "individualization." (p. 12)

The education reform policies were officially enacted in 2003. However, while the new national curriculum was still being piloted in the late 1990s, it encountered heavy opposition from various stakeholders, including teachers, parents, and students (Chou and Ching 2012). Intense public opposition and resistance to the reform created a culture of distrust within Taiwanese society (Tschannen-Moran and Hoy 2000). At the same time, inadequate communication between policymakers and implementers generated uncertainty, anxiety, and insecurity about the reform agenda. In particular, teachers and parents objected to the ambiguity in curriculum guidelines, the lack of professional development and resources for using constructivist and student-centered teaching approaches, and the incongruity between the curriculum and the national examination system. These conflicts widened the gap between the views of the policymakers and those of the general public on education reform policies. Consequently, the Minister of Education, Dr. Yuan-Tseh Lee, apologized to the people of Taiwan in 2002 for the rapid changes in education polices (Shouse and Lin 2010). These issues have led some scholars to conclude that Taiwan's current education reform movement is bound to fail.

Indeed, much of the literature views the implementation of the reform as inefficient or inadequate (Huang et al. 1998; Hwang 2003). Some scholars assert that the policy planning process was insufficient and the rush to implement the reform policies might have led to resistance to change (Chou and Ching 2012; Yang 2000). They also argue that these policies were developed without taking into account the local historical and cultural context. In particular, given that the reform policies were formulated by Western-trained Taiwanese scholars (Law 2002), the policymakers were eager to import Western models of science education into a very different cultural setting. For example, teacher autonomy was promoted without instituting appropriate mechanisms to support teachers during the change process (Chou and Ching 2012).

The literature has also highlighted the challenges involved in implementing the reform policies in Taiwan, but these studies have focused primarily on teacher resistance and the issues that teachers have confronted while trying to use new instructional approaches in their classrooms (Hwang 2003; Shouse and Lin 2010; Yang et al. 2008). There is currently no research on Taiwanese policymakers' rationalities and political motivations regarding the education reform. Given that the historical and sociopolitical contexts are vital for understanding the development of this reform, we now turn to discussing the political activities in Taiwan vis-à-vis the development of science education reform policies.

\section{Political discourses about Confucian traditions and educational changes}

As discussed earlier, Taiwan's citizens initiated a series of intensive protests and demonstrations in the early 1980s to reclaim the democracy promised in Taiwan's constitution. 
Under the presidency of Ching-kuo Chiang, the discourse around Taiwan's democratic movement led to the creation of a new Kuomintang (KMT) government. During this political movement, the American model of democracy was seen as a template for success for Taiwanese citizens. Thus, competing against the old KMT grandees who were born in mainland China, the new KMT government consisted of many young Taiwanese-born leaders, many of whom had been educated abroad (Law 2002). These politicians strongly advocated the promotion of democracy in Taiwan.

Although President Chiang recognized the need for an open political system in the country, he also believed that a Chinese model of democracy must be grounded in traditional Chinese ethics (e.g., loyalty, filial piety, harmony, peace, self-cultivation, benevolence, and respect for the elderly). In particular, President Chiang believed that Confucianism is the root of Chinese culture, such that Confucian ethics and morality must be the foundation of civilization for Chinese society (Lorenzo 2013). As the Analects of Confucius states,

A youth, when at home, should be filial, and, abroad, respectful to his elders. He should be earnest and truthful. He should overflow in love to all, and cultivate the friendship of the good. When he has time and opportunity, after the performance of these things, he should employ them in polite studies. (Confucius, 1891, p. 155)

Indeed, President Chiang's political ideology was evident in several aspects of educational practice in Taiwanese schools. For example, the Analects of Confucius was proscribed as a mandatory subject in all schools to develop students' Confucian virtues (e.g., benevolence to citizens and loyalty to family). With the debate about lifting martial law in the late 1980s, the pro-democratic leaders began to challenge the political ideology of President Chiang. They often identified Confucianism as "the political authoritarianism and cultural imperialism of the pre-democratic Kuomintang" (Fetzer and Soper 2013, p. 33). In addition, Confucius' values of loyalty to the government and social harmony were viewed as a serious impediment to Taiwan's democratic movement (Shi 2007; Tsai 2005).

Later in the 1980s, Teng-hui Lee, a US-educated Taiwanese technocrat, was appointed as Vice President to assist President Chiang in implementing the political reforms. Lee's first step was to abolish martial law in order to create a multiparty democracy (Kagan 2007). Lee later served as Taiwan's president after President Chiang's death in 1988. During the first few years of his presidency, Lee attempted to reduce Taiwan's overreliance on the United States for both trade and military supplies (Lee 1999). At the same time, President Lee was dealing with the tensions resulting from China's agenda for unification with Taiwan in 1995. This political event led to a debate on whether people of Taiwan are culturally "Chinese" or citizens of Taiwan. Under these political pressures, President Lee devised a strategy to strive for Taiwan's independence from China in conjunction with the national democratic movement. In Lee's (1999) view, Taiwanese nationalism was key to the success of Taiwan's independence movement.

To underscore his commitment to enhance "Taiwanese consciousness" (Bedford and Huang 2006, p. 11) among the younger generation, President Lee strived to increase the number of Taiwanese-born scholars serving as KMT officials. During that time, the 
Democratic Progressive Party--the largest opposition party in Taiwan--also resisted the Chinese unification plan and supported Lee's political vision for Taiwan's independence from mainland China. Together, these pro-democratic and pro-independence politicians have strived to establish an independent Taiwanese identity by rejecting elements of "Chineseness" in Taiwan's political and education systems (Fetzer and Soper 2013, p.33). Further, the opposition to "Chinese Confucianism" has led many Taiwanese political and education leaders to demand the removal of topics related to Confucianism from $\mathrm{K}-12$ textbooks on history and Chinese literature.

The vision for democracy and scientific advancement in Taiwan also inspired education reform in the 1990s. As noted above, the Chinese Nationalist Party-the old KMT government-had imposed stringent restrictions on freedom of speech during the martial law regime. The education system, including teacher-education institutions, textbook publishers, and schools, were strictly monitored by the government to inhibit any discussion or criticism of the government policies (Tien 1989). After the lifting of martial law, President Lee's government initiated large-scale systemic reform in response to the popular demand for an education system that emphasized critical thinking and creativity. To this end, the first education reform committee was established by the new KMT government to develop the reform policies related to science and technology education.

Furthermore, President Chen supported the science education reform committee to implement the new policies during his presidency (2000-2008). This committee organized a series of regional policy planning meetings to identify the issues concerning education at the grassroots level. Notably, local teachers and parents were invited to these meetings to provide their input on educational policies. The reform committee worked on the proposal for science education reform from 1996 to 2002 and published its report in 2003. As the Minister of Education, Cheng-sheng Tu, noted in 2007, Taiwan's science education reform movement was laying the foundation for promoting the country's social and economic development.

\section{Scientific literacy and science education reform in Taiwan}

Over the past 40 years, Taiwan's national science education curriculum has gone through tremendous shifts. Prior to President Chiang's ambition for advancing science and technology in Taiwan, the science curriculum primarily focused on developing students' factual knowledge of science. Beginning in the 1980s, policymakers began to emphasize the economic benefits of science education. They believed that developing scientific knowledge in citizens was necessary to prepare students for the workforce. Therefore, before the reform, content-based science curricula focused largely on memorization and regurgitation of scientific knowledge before the reform. Science labs mainly involved following specific instructions to conduct experiments without developing an understanding of the context and application of scientific models.

According to the Ministry of Education, Taiwan (2003a), the focus of Taiwan's science education reform is to develop meaningful scientific literacy so that all citizens can actively participate in the global knowledge-based economy. This vision appears to be deeply inspired by science education reform discourse in the United States (Cheng 2005). In particular, curriculum guidelines in Taiwan bear a striking resemblance to the science teaching standards developed by the American Association for the 
Advancement of Science (2009) and the National Research Council (1996) in the United States (see also DeBoer 2000). The objectives of science education in both countries are to enhance students' engagement in science and to develop their creativity, critical thinking, and problem-solving skills through the application of scientific knowledge (DeBoer 2000; Osborne and Dillon 2008). The opening chapter of the White Paper for Science Education (Ministry of Education, Taiwan 2003a), the most comprehensive reform policy document, states the following:

By comparing the worldwide development, reform and trends of science education to the current implementation of science education in Taiwan, it can be concluded that students around the world are commonly expected to acquire: (1) scientific methods and process skills, (2) scientific knowledge and concepts, and (3) scientific attitudes....[Thus], after careful discussion and consideration, [we] formulated Taiwan's goals of science education as: every citizen should be willing to learn more about science, understand the use of science, enjoy the wonder of science and appreciate the beauty of science. (pp. 12-13)

Since the 2000s, Taiwan's national science curriculum has aimed to develop students' universal scientific literacy and problem-solving skills (Ministry of Education, Taiwan 2003a). Instead of transmitters of knowledge in the classroom, Taiwanese science teachers are expected to act as facilitators of learning. According to the White Paper for Science Education (Ministry of Education, Taiwan 2003a), teachers should adopt "student-centered pedagogy in teaching and evaluation practices" (p. 12). In particular, the curriculum guidelines suggest group teaching (分流教學) as a strategy to foster student-centered pedagogy in K-12 science classes. The most recent Taiwanese Grade 1-9 Curriculum Guidelines (Ministry of Education and Taiwan 2008) also place a strong emphasis on developing students' scientific inquiry skills, creative thinking, and positive attitudes toward science (see also Ministry of Education, Taiwan 2003a, 2011). According to these guidelines, "At the end of K-12 science, all students should be equipped with certain scientific skills, such as inquiry (e.g., observing, inferring, categorizing, and comparing),...critical thinking and problem solving skills to design scientific experiments" (Ministry of Education and Taiwan 2008), p. 3). Table 1 highlights some historical landmarks in science education reform during this period.

As demonstrated above, Taiwan's science education reform discourses were shaped by the democratic movement and political events of the 1990s. After the education reform, the MOE shifted its role from controlling content-based curricula to providing teachers with competency-based guidelines. Teachers now have greater autonomy in choosing content and teaching strategies. However, while Western models of science education have continued to be a priority for policymakers in Taiwan, many science teachers feel unprepared to use constructivist teaching approaches and studentcentered pedagogies (Huang 2014). Thus, while exploring the political rationalities of Taiwan's education reformers, this study also seeks to gain an in-depth understanding of Taiwanese policymakers' perspectives on supporting science teachers to implement the reform-based curriculum and pedagogies. In the following section, we explain the research methods of this study. 
Table 1 Evolution of the secondary science education curriculum in Taiwan

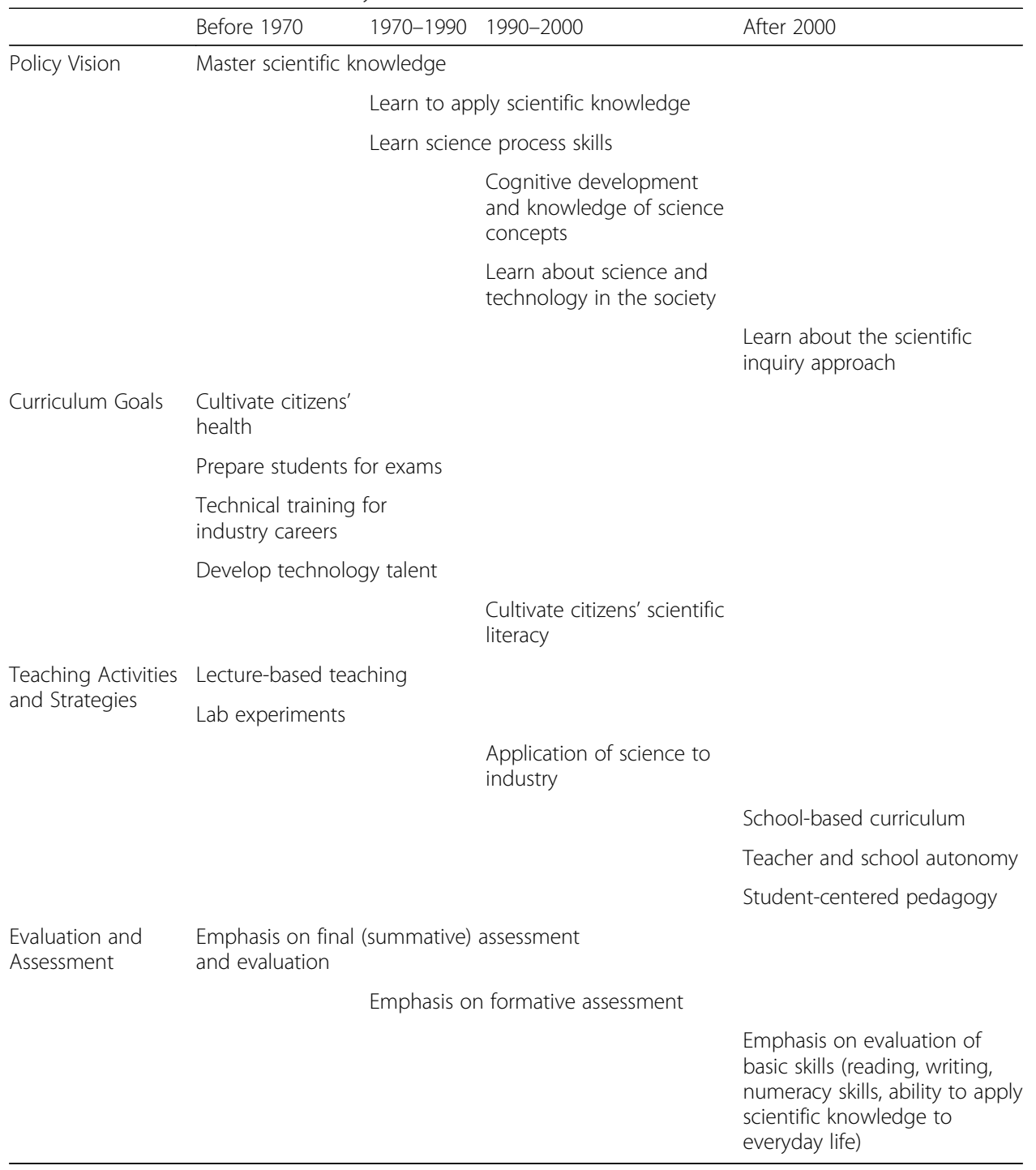

Adapted from Cheng (2005). Wo kuo ke xue jiao yu gai ge de hui gu zhan wan. Science Educaion Monthly, 284, 2-22

\section{Methods}

This study sought to explore Taiwanese policymakers' concerns and visions about education policies and their impact over the last few decades. Through interview conversations with policymakers, it explored the barriers to the implementation of constructivist approaches to science education.

\section{Data collection}

\section{Recruitment of participants}

Following the approval of this study by the McGill Research Ethics Board in April 2013, the first author, using the purposeful sampling method, contacted the education policy leaders who were the main architects of the reform policies. All policymakers who participated in this study have actively contributed to the reform policies while serving on editorial committees for producing policy documents such as the White 
Paper for Science Education (Ministry of Education, Taiwan 2003a). Participants' characteristics and leadership activities are described in Table 2.

\section{Individual interviews}

In order to gain insights into the policy planners' perspectives on these reform initiatives, semi-structured interviews were conducted with three Taiwanese policymakers in 2013. Participants were invited to discuss (1) their vision for science education policy changes in Taiwan, (2) their perspectives on the current implementation of the new science education policy in Taiwanese schools, and (3) their views about professional supports during the implementation process in science classrooms.

Individual interviews lasting from 90 to 120 min were conducted in Mandarin by the first author. These interviews were audio-recorded after obtaining participants' permission. The audio-tapes of the interviews were then transcribed and translated from Mandarin into English by the first author. To enhance the descriptive validity of these interview data, two professional translators were asked to review approximately $60 \%$ of the English translations of the interview transcripts. Both authors discussed and analyzed the translated and de-identified interview transcripts during the interpretive process.

\section{Data analysis}

Thematic analysis (Creswell 2007) was used to categorize important themes and to cluster phenomena associated with study objectives. In particular, thematic analysis helped us to discover salient concepts across participants' individual interview transcripts and the policy documents. We identified a number of central themes through this process (e.g., mechanisms for policy implementation, Confucian learning traditions, etc.). Furthermore, we used the constant comparative method (Denzin and Lincoln 2000; Maxwell 1996) to examine the similarities and differences between the policy documents and policymakers' perspectives on the reform policies. Throughout this analysis, we identified and compared the various factors that posed significant challenges to the implementation of science education reform in Taiwan.

The first author grew up and received her K-12 and college education in Taiwan, earning a bachelor's degree in industrial engineering from a teacher-education institution. She is currently pursuing research in science education in North America. Her

Table 2 Participants' profile

\begin{tabular}{|c|c|c|c|c|}
\hline No. & Pseudonym & Gender & Leadership areas and activities & Contribution to reform policies \\
\hline 1 & Huai-guo a & M & $\begin{array}{l}\text { Science education, Teacher development, } \\
\text { K-12 curriculum development }\end{array}$ & $\begin{array}{l}\text { Served on the science curriculum review } \\
\text { committee }\end{array}$ \\
\hline \multirow[t]{2}{*}{2} & Yang-ming & M & $\begin{array}{l}\text { Science education, Teacher development, } \\
\text { K-12 curriculum development }\end{array}$ & $\begin{array}{l}\text { Member of the core editorial committee } \\
\text { that organized nationwide consultations } \\
\text { with science teachers during the } \\
\text { development of the reform policies, }\end{array}$ \\
\hline & & & & $\begin{array}{l}\text { Served on the science curriculum review } \\
\text { committee to develop the science } \\
\text { curriculum guidelines. }\end{array}$ \\
\hline \multirow[t]{2}{*}{3} & Qian-hua & M & $\begin{array}{l}\text { Science education, National science } \\
\text { policy Higher Education }\end{array}$ & Member of the reform committee. \\
\hline & & & $\begin{array}{l}\text { Talent development program for gifted } \\
\text { students in science and technology }\end{array}$ & $\begin{array}{l}\text { Working at the Ministry of Science and } \\
\text { Technology at the time of this study. }\end{array}$ \\
\hline
\end{tabular}

aPseudonyms were assigned to all participants 
knowledge, personal experiences, and local contacts in Taiwan were invaluable in conducting this study and interpreting participants' perspectives on educational change in the specific cultural, social, and political context of Taiwan. The second author is a science education researcher and has been conducting research to understand the politics of educational reform in diverse international contexts.

\section{Findings}

This exploratory qualitative inquiry aims to identify and assess the challenges that policymakers have encountered while implementing the mandatory reform-based curriculum in Taiwan. This section is divided into two parts. The first part discusses policymakers' visions of science education reform and their perspectives on professional development of teachers. In the second part, we focus on the myriad challenges encountered during the implementation of the reform. In particular, various obstacles to the reform initiative from the policymakers' experience are illuminated.

\section{Policymakers' perspectives on science education reform in Taiwan}

\section{Policymakers' vision for science education reform}

Understanding the reform vision from the policymakers' standpoint was an important objective of this study. The policy leaders explained that enhancing Taiwanese students' scientific literacy was a core element of the reform agenda. From their perspective, scientific literacy was crucial in terms of preparing Taiwanese citizens to participate in civic affairs. As Qian-hua noted, "[Earlier] we used to only emphasize textbook knowledge...but the vision of this reform is to develop citizens' literacy in science." Yang-ming echoed Qian-hua when he stated that "increasing everyone's science literacy" is a key goal of science education reform. In his words, "Whether we're talking about the short-term or long-term goals, in the White Paper, the objective is still to increase everyone's science literacy. This has become the goal of science curricula at all levels of education."

While elaborating on his understanding of scientific literacy, Yang-ming noted that scientific literacy entails developing positive attitudes toward science and "understanding how to use the scientific concepts and skills" rather than "just memorizing a bunch of information."

Huai-guo, who has been involved in formulating policies for teacher preparation programs, added that promoting students' interest and nurturing "diverse talent" were the main reasons for making science the key focus of education reform in Taiwan. Huai-guo added that the curricular reform promoted an "interdisciplinary science curriculum." For example, the secondary biology content was integrated with other disciplines, such as farming, food sciences, medicine, and environmental science. Huaiguo believed that the traditional system lacked diversity and creativity because it focused mainly on preparing students for a professional career in medicine. As he explained, "I hope our education system can embrace diversity....We can support different perspectives....The system won't just produce two kinds of students: those who got into medicine and those who failed their exams."

\section{Policymakers' views regarding teacher preparation and professional development}

The policy leaders pointed out the importance of supporting teachers to implement the reform-based curriculum in their classrooms. Designing ongoing professional 
development programs to support teachers in shifting their practice emerged as a key factor in the implementation process. The policymakers strongly believed in reforming teacher development programs in conjunction with science education reform. Indeed, the participants explained that they have been making efforts to introduce significant systematic changes into the teacher-education system to enhance the quality of pre-service and in-service programs. Emphasizing the importance of continuing professional development in the change process, Huai-guo noted, "In-service education is seen as absolutely [important]....The Ministry of Education and the local educational governments give out a lot of money for inservice teacher training."

In the same vein, the reform policy documents indicated that teacher-education programs were meant to prepare science teachers to effectively implement the reformbased pedagogy. Moreover, providing professional resources to teachers through setting up local teaching communities was an important strategy for promoting the reformbased pedagogy. The participants believed that teachers need extensive professional support to understand the reform policies and explain them adequately to the parents as well. However, two policymakers seemed concerned that teachers were not benefiting significantly from ongoing in-service programs, even though the government had allocated a tremendous amount of financial resources to establish these programs. They were concerned that teachers were not interested in participating in regular in-service training to improve their teaching.

Teacher autonomy was also underscored as an important factor in the reform process by these policy leaders. For example, Huai-guo explained that the goal of the new policy was to provide teachers with greater autonomy in the classroom to empower them to make appropriate pedagogical decisions while using cooperative learning and inquiry-based teaching methods. Since these teaching and learning approaches aim to promote students' creative and critical thinking, teachers need to use a variety of tools and strategies to facilitate their students' learning through inquiry-based tasks. Ultimately, teachers need independence to use reform-based teaching approaches. Thus, encouraging teacher autonomy was viewed as essential to the implementation of creative teaching strategies in the classroom.

The policy leaders stressed the need to infuse creative pedagogical approaches in teacher-education programs because they felt that teacher training programs (both preservice and in-service) tended to ignore the importance of cultivating creativity in students. In addition, teachers' ability to differentiate and align instruction with students' interests and needs was also deemed important to fostering "students' diverse interests, capacities, and skills" while learning science.

\section{Challenges to the implementation of science education reform Tensions between parents' expectations and the reform goals}

The participants discussed a number of critical issues confronting the implementation of the reform policies. Specifically, they shared difficulties in executing the education policies outlined in the White Paper for Science Education (Ministry of Education, Taiwan 2003a). One participant even described the White Paper for Science Education as an "ideal proposal" for Taiwanese schools. They believed that the reform policy was not yet widely understood and accepted by teachers, parents, and students. For 
example, Yang-ming was concerned about the tension between parents' cultural values and the reform agenda. He also pointed out the incongruity between parents' perceptions of teaching and the new curricular approaches. He believed that parents valued traditional teaching approaches and therefore teachers were "afraid" of trying out new ways of teaching. According to him,

Teachers cannot persuade parents, as they [teachers] cannot change their [parents'] cultural values in Taiwan....[T] eachers are so afraid of testing and changing their teaching methods....I don't know what we could do to help teachers. They just want to teach in a traditional way because it is generally acceptable by the society.

While elaborating on parents' perspectives in relation to educational change, the participants discussed the role of parents' expectations about their children's academic performance in national examinations. In particular, they believed that these expectations force teachers to "teach to the test." Consequently, parental pressure poses a massive challenge to inquiry-based curricula that engage students in active learning and critical thinking. Huai-guo explained that parents' expectations were deeply entrenched in the prevailing societal notions of success. He believed that "parents will never comprehend [the reform], as they basically want their children to perform well on the exams." In Huai-guo's opinion, success in standardized national and international assessments does not mean that the education system in Taiwan is effective. In his words,

It doesn't mean that our education is successful even though our students perform well on international competitions like PISA and TIMSS [Trends in International Mathematics and Science Study]. It is because we memorize for exams. However, parents will never be able to comprehend [open-ended inquiries] because we have always thought that knowledge should be memorized.

Like Huai-guo, Yang-ming maintained that parents insist on preparation for standardized exams because they want their children to achieve high scores required for entry into the medical profession. This issue has negatively affected the implementation of new approaches to science teaching. Yang-ming further elucidated this point:

The influence of examination is a societal value rather than a simple educational problem. It's a societal value because it's deeply ingrained within the heart of parents, everyone. Hence, this societal value affected the science education policy and practice. Teachers have no choice but to practice as the society expects them to....Since cram schools offer all kinds of science subjects, it's difficult to for society to accept the new method of developing scientific skills.

Qian-hua also shared this perspective and noted that the huge gap between policy and practice was mainly due to cultural expectations about the role of science education in preparing for competitive professional careers and social mobility. Qian-hua explained that parents opposed learner-centered approaches because they believed that lecture-based instruction was the best way to prepare their children for national exams. As Qian-hua stated, 
Parents' pressure is easy to explain. Whenever you change something new, they [parents] panic. Parents are so used to sending their children to cram schools [to prepare for exams]. But now, even cram schools do not know how to teach [using inquiry]. Of course, parents panicked, so they rejected this policy.

\section{Confucian learning traditions as a challenge to educational change}

As we discuss policy leaders' perspectives on Confucian learning traditions and their impacts on Taiwan's education system in this section, we present direct quotations from study participants in order to avoid misrepresenting participants' interpretations of Confucian values.

While one participant candidly shared his discomfort while discussing local Confucian values during the interview, the other two policy leaders appeared to share an interpretation of the impact of Confucian values on Taiwan's education system. They asserted that contemporary developments in education could not be sustained without a transformation of Taiwan's traditional learning culture. They specifically identified the ways in which Confucian learning principles have profoundly shaped Chinese educational traditions for centuries. According to Huai-guo, "Confucianism emphasized collectivism, harmony in family and community, which conflict with the notion of individualism in Western cultures." He further added,

Collective thinking about establishing a balanced social order has led the society to prioritize discipline and rules without considering the long-term effects of these values. Collectivism affects the format of science education rather than content. All teachers want students to be well behaved and follow cookbook procedure during experimentation. Societal impact definitely exists. People who are making policies are also influenced by society, by militarism, which empowers collectivism. This is how strongly Confucianism is influencing Taiwanese. It's difficult to go on any other path without appropriate countermeasures.

Huai-guo continued,

Widespread acceptance of Confucianism restricts the space for developing new ideas or values in society. The dominance of these values affects science classroom practice, since teachers mainly ask their students to behave in a disciplined manner and conduct structured science experiments by following the directions given in the textbooks. Teachers do not encourage innovative thinking and other scientific skills, [such as] critical thinking and problem-solving skills,...which affects the development of scientific knowledge in society (Huai-guo).

Huai-guo argued that in order to reform educational practice, "students have to change the perception that teachers and textbooks are always right; teachers have to accept that students can challenge the authority and expertise of teachers." Reiterating Huai-guo's point, Yang-ming noted, "The emphasis on conformity and respect for tradition has prevented the implementation of nontraditional teaching methods in the formal education system....It's difficult for the society to accept the inquiry method, as it [disrupts] discipline." Qian-hua agreed with these views on the role of Confucian traditions vis-à-vis the reform. He believed that Confucian values "have impeded the 
progress of science in this country." He maintained that innovative and creative ways of thinking might be viewed as a sign of disrespect in Taiwan because respect for elders and traditional norms is considered an important value in this society.

Qian-hua was also concerned about the overemphasis on Confucian learning culture in Taiwanese society. He argued that Confucian cultures tended to value tradition, knowledge, and collective thinking over individual opinions and technical skills. According to him,

In Confucian cultures, functionalism, collective thinking, acting according to tradition....are important characteristics....[K]nowledge, professional education, and credentials are valued more than technical, hands-on skills. These are obstacles to scientific advancement...and the reason why science in Asia cannot advance (Qian-hua).

Qian-hua continued,

Traditional culture within the Confucius heritage and Asian culture often treats science....as a tool. It's a tool for moving up the social ladder. Since the motivation to move up is strong, students are forced to study knowledge that is being tested. This would not happen in the West where parents do not force children to study....These Confucian traditions thus have impeded the progress of science in this country (Qian-hua).

In sum, the national examination system was highlighted by the policymakers as the main challenge to the reform. In addition, they seemed to share a fairly clear position in regards to the challenges posed by Confucian traditions to the reform. We reiterate here that these findings and interpretations of Confucianism may not represent the views of all science policy leaders in Taiwan. The perspectives of the three participants reflect their personal, professional, and political positions on educational reform and offer useful insights into the intricate dynamics of educational reform in a Confucian learning culture.

\section{Discussion}

The primary focus of this study was to explore the dynamics of contemporary science education reform in an East Asian culture. The goal was to explore the ways in which education reform was intimately related to the political movement for democracy in Taiwan. Before embarking on this research, we examined the policy documents and curriculum guidelines to understand how reform goals intersected with the new vision for social and political change. The government documents and official guidelines served as useful resources for looking at the trajectory and philosophical foundations of Taiwan's science education reform movement.

The analysis of the policy leaders' perspectives about the reform agenda illuminated multifarious discourses about the reform policies and their implementation in the Taiwanese context. The reform policies in Taiwan place a special emphasis on reforming and modernizing science curricula in line with current developments in Western contexts. The overarching aim of $\mathrm{K}-12$ science education is to develop 
students' scientific literacy through learner-centered pedagogical approaches. This vision draws its inspiration from the curriculum reform discourses in many Western countries, particularly the United States, which emphasize student-centered and inquiry-based pedagogy to develop students' autonomy, creativity, and critical thinking. Hence, teachers are expected to create appropriate teaching and learning materials and adopt new pedagogical practices to encourage students' active participation in learning.

As Foucault (1979) reminded us, policymakers' political motivations and actions are not intrinsically negative. The governmentality framework served as a useful tool to learn from the historical events in Taiwan and examine their "political rationality's very roots" (Foucault 1978, p. 254). Our analysis suggests that the political rationale for education reform in Taiwan rested on two key goals: (1) developing and sustaining a democratic political system and (2) strengthening economic growth. The education reform goals are intimately tied to the national vision for industrial and economic progress through building a strong foundation in science and technology education and research. The rationale in the policy documents hinges on the crucial importance of scientific knowledge and innovation to strengthen Taiwan's economy. The education reformers' rationale for science education centered on fostering scientific literacy and critical thinking to prepare Taiwanese citizens for meaningful civic participation. The government enacted various policies and laws to overhaul the existing $\mathrm{K}-12$ science and teacher-education systems. Importantly, the Western model of science education was deployed as a vehicle to restructure the education system to realize the vision for democracy and economic development. The historical and political conditions that shaped the reform discourses helped to contextualize the complementary visions emerging from the policy frameworks and policy leaders' perspective regarding the rationale for the reform (Foucault 1998).

As explained earlier, Taiwan's education reform initiatives emerged from the political movement for democracy. Indeed, scientific literacy was viewed as integral to the development of a modern democratic society in Taiwan. The conjoining of political and economic ambitions during the movement for democracy in the 1990s led to the massive reform initiative in science education. Taiwan's strong history of partnership with the United States in the field of education as well as their cooperation in science and technology significantly informed the science education policy frameworks in Taiwan-the science curriculum guidelines resonate with the American science education standards for K-12 education (Cheng 2005). It is also important to note that the science education reform policies were largely constructed by Taiwanese scientists who had received their professional education in the United States. Their exposure to democratic values and science education reform discourses thus inspired them to emphasize the value of fostering critical and independent thinking through scientific inquiry (Law 2004).

Nevertheless, the reform policies met with strong resistance from the public. Some scholars argue that the rush to implement these policies might have resulted in tremendous resistance by teachers and parents (Chou and Ching 2012; Hwang 2003). As discussed earlier, the reform in science education was initiated by President Lee's government in the late 1990s and implemented by President Chen's government in the early 2000s. Within a decade, a series of legal and structural changes was introduced in the education system, including the formulation of new laws pertaining to education, the development of new guidelines for teacher preparation and continuing professional 
development programs, and the introduction of student-centered and process-oriented pedagogical approaches in the national science education curriculum (Chen 2013). The policymakers who participated in this study believed that Taiwanese society was not yet ready to accept the rapid changes in education policy. At the same time, they also felt that the examination-oriented learning culture and traditional teaching approaches that focus mainly on preparing students for the national exams have posed enormous challenges to the reform initiatives. While explaining the possible reasons for intense resistance to the reform, Chou and Ching (2012) contended that the reform committee seemingly overlooked the role of social values and learning traditions while articulating the reform policies.

However, the most important finding of this study is that the policy leaders were in fact fully aware of the incongruities between Western models of science education and Taiwanese cultural learning traditions. According to the policymakers, Taiwanese parents and teachers tend to believe that preparing students for national examinations is the primary focus of education. Similarly, many scholars suggest that the primary goal of education in East Asian Confucian learning cultures (e.g., Taiwan, Hong-Kong, Singapore, Japan, and South Korea) is to enable the students to achieve the highest moral standards in the society by developing Confucius' virtues, such as respect for the elderly, loyalty to the government, and a sense of social responsibility (Biggs 1998; Ho et al. 2001; Li 2003). Respect for teachers and their knowledge is also deeply rooted in Confucian learning cultures. Teachers are seen as role models for their students within these cultures. They are expected to pass down their knowledge, wisdom, and cultural traditions to their students. Thus, most teachers and parents cannot be convinced of the effectiveness of active learning and student-centered pedagogical approaches which encourage students to actively construct knowledge through discussion, debate, and experimentation (see also Berry 2011; Yang et al. 2008). The emphasis on conformity and maintaining classroom discipline further challenges the implementation of nontraditional teaching methods in local schools.

Regardless of the public resistance to the reform, President Chen continued to support the committee responsible for science education reform in implementing the new policies that were developed throughout Lee's presidency. President Chen (2000) reiterated his commitment to the reform agenda during his inauguration speech: "We [the new government] will seek a consensus among the ruling and opposition parties, academia and the public to carry on with educational reforms" because these reform policies would enable "Taiwan to cultivate first-class, outstanding talents amid the fierce international competition" (p. 9).

As discussed in earlier sections, Taiwan's transformation into a democracy involved reducing the control of the totalitarian KMT government in the education system. It also inspired science education reform in the 1990s. At that time, both President Lee and President Chen focused on sustaining Taiwan's democratic efforts through the advancement of science and technological innovation. Therefore, they advocated the type of education system and science curriculum used in the United States to promote Taiwan's social development. At the same time, the political ideology of both President Lee and President Chen--to pursue Taiwan's independence--has led many youngergeneration politicians to endorse Taiwanese nationalism (Lee 1999). They have also called for the removal of Chinese nationalism and Confucian traditions from Taiwan's 
educational practices. Such political discourses on rejecting Chinese Confucianism, as Foucault argued, play a vital role in constituting a particular "political regime of truth" (Foucault and Gordon 1980, p. 207). This regime of truth, in Foucault's words, is "the status of those who are charged with saying what counts as true" (Foucault and Gordon 1980, p. 207).

The Taiwanese education reformers in our analysis believed that traditional values tend to conflict with the development of modern science. In particular, these policymakers perceived Confucian values of respect for elders and teachers as obstacles to promoting students' critical and innovative thinking. They believed that the emphasis on maintaining harmonious social order in Confucianism has led to excessive social conformity, which impedes scientific productivity and technological innovation in East Asian societies. They believe that, in order for Taiwan's education system to advance, the impact of Confucian values on educational practices must be lessened and that an American approach to education could help to improve Taiwanese students' active participation in discussions and develop their critical thinking ability, which are claimed to be essential skills in an advanced democratic society.

However, in our view, Taiwan's education reformers seem to have amalgamated traditional Confucian virtues with the Chinese nationalism of the pre-democratic KMT regime. They seemed to be wrestling with the authoritative controls of the martial law regime while believing they were challenging traditional Chinese ethics (e.g., loyalty, filial piety, and harmony) and Confucian values of respect for elderly and loyalty to the government. Aligned with our analysis, Fetzer and Soper (2013) found that many prodemocratic politicians and Taiwanese social elitists view traditional Confucian values as inherently authoritarian. Consequently, they claim to reject Confucian morality due to its use by the totalitarian KMT government. For them, respecting Confucian values and traditions was used strategically by the old KMT grandees as "ideological justification" to "openly suppress" Taiwan's evolution to democracy (Fetzer and Soper 2013, p. 34). Similarly, education reformers in this study also contended that their efforts to advance Taiwan's science education have often been hampered by the influence of traditional Confucian values in Taiwanese society. Although the study participants might interpret Confucianism and Confucian traditions differently, this empirical exploration offers readers critical and meaningful insights into political and historical perspectives on the reform.

In our analysis of data obtained through interviews with science teachers, we found that most Taiwanese science teachers emphasized the importance of Confucian ethics for society at large (Huang and Asghar, in press). They often found that reform-based pedagogies are not compatible with their cultural beliefs about teaching and learning (e.g., Confucian values of respect for the elderly, the meaning of classroom discipline, and ways to promote a harmonious learning community). These beliefs have led teachers to feel that policymakers and education reformers seem to not understand the professional needs of teachers. While educational reformers have attempted to use the new science curriculum to diminish the influence of Confucian values in Taiwanese schools, most science teachers felt that policymakers have proposed a reform agenda that is not aligned with the professional needs of teachers. This lack of consensus between Taiwanese teachers and policymakers has led teachers to feel a general lack of commitment to the new curriculum (Huang 2014). 
In light of the above, this study examines the effects of governmental rationality on the development of education reform in Taiwan. The goal is to provoke discussion about the necessity of confronting traditional Confucian values while improving science education in Taiwan and other East Asian countries. Such discussions, Foucault and Gordon (1980) argued, are important, as they help to uncover "the political regime of truth (p. 133)," such that the possibilities of different forms of educational change could be explored.

\section{Conclusion}

This work unravels the intricate connections among economic, political, and educational reform agendas in Taiwan. In this way it contributes fresh insights to the literature on the significance of science education reform to the development of a modern and progressive Taiwan. The study argues that educational change in Taiwan needs to be examined in the context of historical and political conditions to achieve a comprehensive understanding of the vision, goals, and mechanisms for the reform. This study shows that science education reform efforts were closely connected to the political reform movement in Taiwan. Indeed, education reform was used as a vehicle to promote changes in the traditional political system to establish democratic institutions and processes in the country.

The political leaders were aware of the clash between the traditional cultural norms and the modern education system. Hence, they developed a comprehensive rationale to justify the modernization of the education system. Their argument centered on the need to promote economic development through the creation of a knowledge-based economy in Taiwan. Thus, advancement in science and technology was crucial to achieving this objective. At the same time, they believed that inquiry-based approaches in education would promote individual thinking, creative ideas, and freedom of expression in the younger generation, who would then be able to participate in and sustain a democratic political system in Taiwan. These developments would ensure international recognition of Taiwan's identity as an independent and developed country.

This study sheds light on the role of decision makers' political ideologies--both conscious and unconscious--in the process of education policy planning and implementation. Taking the governments' political motivations for education policy into account helps education leaders and scholars to rethink issues related to policy implementation, such as teachers' resistance to change, in a different way. For example, while many scholars have pointed to the potential incompatibility between Western standards of science education and Eastern values of teaching and learning, for what political reasons does the Taiwanese government continue to adopt Eurocentric science standards such as PISA and TIMSS? These complex political issues are generally not discussed in the literature on education reforms in Eastern countries. Attending to these culturally and politically specific issues illuminates the impediments to effective planning and implementation of education reform. Therefore, this research advances our understanding of the preliminary problems involved in education development in Taiwan and other countries with similar political and social contexts.

A number of important questions have emerged from this work which could be investigated through future studies. For example, what other historical and political conditions might have shaped the development of policy and invoked different forms of 
discourse? In what ways can we learn from the experience of implementing Western models of science education in East Asian cultures? In what ways do global discourses intersect with local needs in shaping educational change in the context of Taiwan as well as in other East Asian countries? This exploration has also opened up a new space for a dialogue on the interactions between Confucian traditions and contemporary approaches to education. Future studies could explore the perspectives of other stakeholders-parents, politicians, entrepreneurs, practitioners, and scholars-to achieve a holistic understanding of the reform discourse.

\title{
Authors' contributions
}

HY-S conceived the study; participated in its design, coordination, and data analysis; and drafted and revised the manuscript. AA made substantial contributions to conception and design, data analysis, and interpretation of data, and was involved in revising the manuscript critically for important intellectual content. Both authors read and approved the final manuscript.

\section{Competing interest}

We declare that we have no significant competing financial, professional or personal interests that might have influenced the performance or presentation of the work described in this manuscript.

\begin{abstract}
Authors' information
Ying-Syaun Huang is a full-time doctoral student in the Math and Science Education Concentration program at McGill University. She graduated from National Taiwan Normal University with a Bachelor of Engineering in Graphics Arts and Communications and earned her Master of Arts in Education and Society at McGill University. Anila Asghar is an Associate Professor in the Department of Integrated Studies in Education at McGill University. Prior to joining McGill she was an Assistant Professor at the Johns Hopkins School of Education. She received her doctorate in Education from Harvard University and did postdoctoral research at the Evolution Education Research Center at McGill University.
\end{abstract}

Received: 19 November 2015 Accepted: 31 August 2016

Published online: 15 September 2016

\section{References}

American Association for the Advancement of Science. (2009). Benchmarks for science literacy online. Oxford: Oxford University Press.

Ball, S. J. (1994). Education reform: A critical and post-structural approach. Buckingham, England: Open University Press.

Ball, S. J. (2012). Politics and policy making in education: Explorations in sociology. Abingdon, Oxon: Routledge.

Barry, A. (1991). Government in Foucault. Canadian Journal of Philosophy, 21(4), 421-440.

Bedford, O., \& Huang, G. (2006). Taiwanese identity and democracy: The social psychology of Taiwan's 2004 elections. New York: Palgrave Macmillan.

Berry, R. (2011). Educational assessment in mainland China, Hong Kong and Taiwan. In R. Berry \& B. Adamson (Eds.), Assessment reform in education: Policy and practice (pp. 49-61). Dordrecht, Netherlands: Springer.

Biggs, J. (1998). Learning from the Confucian heritage: So size doesn't matter? International Journal of Educational Research, 29, 723-738.

Cai, T.-T. (2001). Shijian Xuexiao Benwei Kecheng Fazhan Linian De Zhuanye Xingdong [Professional practice and implementation of school-based curriculum]. Jiaoyu Yanjiu Yuekan [Journal of Education Research], 88, 24-34.

Chen, S-B. (2000). Taiwan stands up: Toward the dawn of a rising era. President Chen Shui-bian's Inauguration Speech. Avaiable on Taipei Times: http://fas.org/news/taiwan/2000/e-05-20-00-8.htm.

Chen, S. H.-L. (2013). Tawian: Trends and agenda in education reform. In P.-T. J. Hsieh (Ed.), Education in East Asia (pp. 257-278). London: Bloomsbury Academic.

Cheng, Y.-J. (2005). Wo kuo ke xue jiao yu gai ge de hui gu zhan wan. Science Educaion Monthly, 284, 2-22.

Chou, C. P., \& Ching, G. (2012). Taiwan education at the crossroad: When globalization meets localization. New York: Palgrave Macmillan.

Confucius (1891). Confucius analects. In H. Coppée (Ed. \& Trans). The classic and the beautiful from the literature of three thousand years (pp. 154-164). Philadelphia: Carson \& Simpson

Creswell, J. W. (2007). Qualitative inquiry and research design: Choosing among five approaches. Thousand Oaks, CA: Sage.

DeBoer, G. E. (2000). Scientific literacy: Another look at its historical and contemporary meanings and its relationship to science education reform. Journal of Research in Science Teaching, 37(6), 582-601.

Denzin, N. K., \& Lincoln, Y. S. (2000). Handbook of qualitative research. Thousand Oaks, CA: Sage.

Fendler, L. (2010). Michel Foucault. London: Continuum.

Fetzer, J. S., \& Soper, J. C. (2013). Confucianism, democratization, and human rights in Taiwan. Lanham: Lexington Books.

Fimyar, O. (2008). Using governmentality as a conceptual tool in education policy research. Educate $\sim$ The Journal of Doctoral Research in Education, 1(1), 3-18.

Foucault, M. (1978). The history of sexuality. New York: Pantheon Books.

Foucault, M. (1979). Discipline and punish: The birth of the prison. New York: Vintage Books.

Foucault, M. (1998). Polemics, politics, and problematizations. In P. Rabinow (Ed.), Essential works of Foucault 1954-1984 (Vol. 1, pp. 111-120). New York: The New Press. 
Foucault, M., \& Gordon, C. (1980). Power/knowledge: Selected interviews and other writings, 1972-1977. New York: Pantheon Books.

Foucault, M., \& Rabinow, P. (1984). The Foucault reader. New York: Pantheon Books.

Ho, D. Y. F., Peng, S. Q., \& Chan, S. F. F. (2001). Authority and learning in Confucian-heriatge education: A relational methodological analysis. In C. Chiu, F. Salili, \& Y. Hong (Eds.), Multiple competencies and self-regulated learning: Implications for multicultural education (pp. 29-48). Information Age: Greenwich, CT.

Huang, Y.-S. (2014). Science education reform in Confucian learning cultures: policymakers' and science teachers' perspectives on policy and practice in Taiwan (Unpublished master's thesis). Montreal, Canada: McGill University.

Huang, Y-S, Asghar, A. (in press). Science education reform in Confucian learning cultures: teachers' perspectives on policy and practice in Taiwan. Cultural Studies of Science Education.

Huang, I., Aldridge, J. M., \& Fraser, B. (1998). A cross-national study of perceived classroom environments in Taiwan and Western Australia: Combining quantitative and qualitative approaches. Chinese Journal of Science Education, 6(4), 343-362

Hwang, K. K. (2003). What's wrong with Taiwanese education reform. Taipei: INK Publishing.

Kagan, R. C. (2007). Taiwan's statesman: Lee Teng-Hui and democracy in Asia. Annapolis, MD: Naval Institute Press.

Kyriacou, C., \& Chien, P. Y. (2004). Teacher stress in Taiwanese primary schools. Journal of Educational Enquiry, $5(2), 86-104$.

Law, W. W. (2002). Education reform in Taiwan: A search for a "national" identity through democratisation and Taiwanisation. Compare, 32(1), 61-81.

Law, W. W. (2004). Translating Globalization and democratization into local policy: Educational Reform in Hong Kong and Taiwan. International Review of Education, 50(5-6), 497-524.

Lee, T. (1999). The road to democracy: Taiwan's pursuit of identity. Tokyo: PHP Institiute, Inc

Lemke, T. (2002). Foucault, governmentality, and critique. Rethinking marxism, 14(3), 49-64.

Li, J. (2003). The core of Confucian learning. The American Psychologist, 58(2), 146-147.

Lorenzo, D. J. (2013). Conceptions of Chinese democracy: Reading Sun Yat-Sen, Chiang Kai-Shek, and Chiang Ching-Kuo. Baltimore, MD: Johns Hopkins University Press.

Lu, T., Cowie, B., \& Jones, A. (2010). Senior high school student biology learning in interactive teaching. Research in Science Education, 40, 267-289.

Maxwell, J. A. (1996). Qualitative research design: An interactive approach. Thousand Oaks, CA: Sage.

Ministry of Education, Taiwan (2003a). White paper for science education. Taipei: Ministry of Education, Republic of China

Ministry of Education, Taiwan (2008). Grade 1-9 curriculum guidelines. http://www.k12ea.gov.tw/ap/sid17_law.aspx. Accessed 10 Nov 2015.

Ministry of Education, Taiwan. (2011). White paper on international education for primary and secondary schools. Taipei: Ministry of Education, Republic of China.

National Research Council. (1996). National science education standards: Observe, interact, change, learn. Washington, DC: National Academy Press.

Olssen, M. (1999). Michel Foucault : Materialism and education. Westport, CT: Greenwood Press.

Osborne, J., \& Dillon, J. (2008). Science education in Europe: Critical reflections. London: Nuffield Foundation.

Pongratz, L. A. (2006). Voluntary Self-Control: Education reform as a governmental strategy. Educational Philosophy and Theory, 38(4), 471-482

Rose, N. (1999). Powers of freedom: Reframing political thought. Cambridge: Cambridge University Press.

Rose, N., \& Miller, P. (1992). Political Power beyond the State: Problematics of Government. The British Journal of Sociology, 43(2), 173-205.

Shi, Z. (2007). Democracy (made in Taiwan): The "success" state as a political theory. Lanham: Lexington Books.

Shouse, R. C., \& Lin, K. P. (2010). Principal leadership in Taiwan schools. Lanham, MD: Rowman \& Littlefield.

Tien, H. (1989). The great transition: Political and social change in the Republic of China. Stanford, CA: Hoover Institution Press,

Tobin, K., \& McRobbie, C. J. (1996). Cultural myths as constraints to the enacted science curriculum. Science Education, 80(2), 223-241.

Trowler, P. (2003). Education Policy. New York: Routledge.

Tsai, S. H. (2005). Lee Teng-hui and Taiwan's quest for identity. Hampshire: Palgrave Macmillan.

Tsai, C.-C., \& Kuo, P.-C. (2008). Cram school students' conceptions of learning and learning science in Taiwan. International Journal of Science Education, 30(3), 351-373.

Tschannen-Moran, M., \& Hoy, W. K. (2000). A multidisciplinary analysis of the nature, meaning, and measurement of trust. Review of Educational Research, 70(4), 547-593.

Tu, CS (2007). Taiwan's educational reform and the future of Taiwan. Invited speech at the London School of Economics and Political Science, 10 Jan. http://www.Ise.ac.uk/researchAndExpertise/units/TaiwanProgramme/ Events/PublicLectures/TaiwanEducationalReform_English.pdf. Accessed 26 July 2015.

Yang, F., Chang, C., \& Hsu, Y. (2008). Teacher views about constructivist instruction and personal epistemology: A national study in Taiwan. Educational Studies, 34(5), 527-542.

Yang, S. K. (2000). Education reform facing the new millennium: Methodological reflection and international comparison. Jiaoyu Yanjiu Jikan [Bulletin of Educational Research], 44(1), 34-60. 